\title{
Using Thinking Routines as a Pedagogy for Teaching English as a Second Language in Palestine
}

\author{
Majida "Mohammed Yousef" Dajani \\ Al-Quds Open University and Al-Eman Schools
}

\begin{abstract}
This study examined the results of promoting Palestinian students' engagement and fostering their understanding in addition to their inquiry skills through the application of thinking routines. Six teachers teaching fourth and fifth grades participated voluntarily in this action research project during the school year 2014-2015. The researcher videotaped a number of classes, collected and discussed teachers' and students' reflections, and analyzed classroom observation reports. During the data collection process, the researcher depicted and narrated common themes and issues retrieved from the different sources that were used to collect data. Results revealed that the implementation of visible thinking routines in English language classrooms was a challenge for both the learners and the teachers. For the learners, the challenges were their limited abilities to express themselves using English language, and for the teachers, the challenges were the extra effort that they needed to exert because it was their first experience in implementing such routines. Teachers sometimes found it difficult to decide which thinking routine is appropriate to the activities they wanted to implement. However, teachers asserted that positive changes occurred in English language classrooms and in students' learning and interaction. Teachers expressed their admiration of how students were more engaged to explore, connect ideas, and delve deeper for better understanding of topics discussed. Classroom activities became more enjoyable, more learning directed and more learners centered. In the light of the research results, Palestinian teachers were recommended to use thinking routines to promote students' engagement and foster their understanding.
\end{abstract}

Keywords: culture of thinking, engagement, thinking routine, visible thinking, understanding, inquiry skills

\section{Introduction}

Teachers have different roles in English language classrooms, but one of the most important roles is to teach students how to become skilled thinkers to promote their understanding and their intellectual development as these are the major goals of education in this fast moving competitive world. Thinking usually happens in students' heads, but unfortunately it is not visible either to teachers or to students themselves (Ritchhart \& Perkins, 2008). This means that teachers continuously need to provide stimulating and supporting activities that engage learners in thinking. Teachers need to work hard on externalizing students' thoughts through speaking, writing, drawing, questioning, and documenting, and all this should be consistent with modeling and encouragement by teachers and parents.

Please address queries to: Majida "Mohammed Yousef” Dajani, Al-Quds Open University and Al-Eman Schools. Email: majidad4@hotmail.com 
Promoting students' thinking skills and fostering their understanding and their intellectual development might be achieved through the application of thinking routines. Unfortunately, Palestinian teachers are not fully aware that thinking routines form the core of visible thinking (VT) that promotes the development of students' thinking skills. Thinking routines are the cornerstones for engaging and involving students in their classroom activities and tools for teachers to follow their students' thinking processes that help them discover their knowledge, misconceptions, reasoning ability, and understanding.

Making thinking visible must be at the heart of improving teaching and learning English as a second language (ESL) in Palestinian English language classrooms. With the current Palestinian traditional teaching methods, students' thinking processes are often invisible and are not well enhanced and developed. However, through the implementation of thinking routines, students are expected to externalize their thoughts, ideas, beliefs, thinking processes, and deep understanding.

Thinking routines are a series of questions that English language teachers can use in their classes to lead students to steps of critical thinking. These series of questions open children's minds to observe, think, inquire, and delve into deeper thinking processes. Many researchers emphasize that using thinking routines in English language classrooms helps in making our students' thinking visible (Ritchhart, Church, \& Morrison, 2011; Ritchhart \& Perkins, 2005; Salmon, 2008).

In this study, thinking routines were opportunities to enhance students' thinking skills to lead students to a better engagement in classroom discussions and thus enhance their inquiry skills and understanding. Thinking routines were steps for exploring ideas and investigating the content studied in English language textbooks.

\section{Background of the Study}

Under occupation, with the lack of resources, developing teaching skills remains a major concern in Palestine. Palestinian teachers face many problems and obstacles related to educational quality, low salaries, lack of administrative and supervisory support, poor work conditions, lack of resources, and increased workloads (Khaldi \& Wahbeh, 2002; Kouhail, 2004). Moreover, teachers are not well trained in teaching as a whole, nor are they trained or supported to use different methods and techniques to teach the Palestinian curriculum (Dajani, 2015).

Therefore, and to address some of in service training problems, the Palestinian Ministry of Education and the America-Mideast Educational and Training Services are jointly implementing a Leadership and Teacher Development (LTD) program to improve the quality of school education in Palestine. This program started in the fall of 2012 and will continue until the spring of 2016. LTD intends to develop a school based community of educators who share a common understanding of the importance of the application of good teaching practices for a better future for Palestinians. The LTD program tries continuously to equip teachers with the necessary tools to implement changes to improve students' learning in Arabic, in English second language acquisition, the sciences, mathematics, and technology education (America-Mideast Educational and Training Services, 2014). It is essential to make use of the LTD program to address persisting challenges and to enhance efforts to improve teaching ESL in Palestinian schools.

In Palestine, ESL is taught as a subject in schools. Students in ESL classes show their thoughts through speaking, writing, dialoguing, answering questions, and in very few cases dramatizing. ESL in Palestine is taught from first grade, but unfortunately a large number of students end 12th grade and still face difficulties in producing the language and in elaborating and questioning their thinking 
in English. This is because classrooms are more grammar oriented and student learning is often directed towards rote memorization and regurgitation. The communicative aspect of language is not extensively developed.

\section{Research Problem}

As an English language supervisor at a private school in Jerusalem and as a teacher trainer in the LTD program, I have observed the ESL classroom practices as do many other ESL classes all over the world. ESL classes seem only to manage student behavior, teaching strategies, and classroom interactions. ESL classes establish rules for managing students' communication and participation, but unfortunately, English language teachers seldom apply classroom thinking routines.

The goal of ESL teachers is almost always based on completion of work and students' preparation for tests. Grades are the outcome of the completed work that is based on rote learning. Students often do the work without questioning because the focus is not on deep learning, but on having the right answer and getting good grades. Unfortunately, some parents are even more concerned with their children grades than with their critical thinking or deep understanding.

Teachers sometimes ask students to think, but they have seldom stepped back to consider what they actually want their students to do and what processes they should follow in order to enhance their thinking skills. The other problem might be related to the fact that, to the best of researcher knowledge, not much has been said about the role of VT in ESL pedagogy and its implication in Palestinian schools.

The other noticed problem is that English language teachers often ask closed-convergent questions though questioning lies at the heart of learning and teaching. Thinking routines help teachers and students develop their questioning techniques and inquiry skills. This study is important in the Palestinian context, as it addresses the scarcity of relevant data and literature on the implementation of thinking routines in English language classrooms; thus, it could both bridge the gap in the current research literature and consolidate the existing literature.

\section{Purpose of the Study}

The purpose of this study was to investigate the impact of the implementation of thinking routines on students' engagement, inquiry skills and understanding to develop and improve learning ESL in Palestinian schools. It also aimed to study and discuss the changes that took place (if any) with a particular focus on the extent of reflection practiced during the implementation of thinking routines.

\section{Research Questions}

The study addressed the following two questions:

1. What is the impact of thinking routines on promoting students' engagement and fostering their understanding?

2. What are teachers' and students' reflections regarding the changes that take place as a result of the implementation of thinking routines? 


\section{Conceptual Framework}

VT is a flexible framework for enhancing and enriching classroom learning. It includes a number of ways to make students' thinking visible to themselves, to their peers, and to their teachers so that they get more engaged and involved in the activities implemented in classrooms. Research asserts that VT is designed to foster abilities, attitudes, and alertness (Ritchhart et al., 2011). Fostering increased learning abilities, improved attitudes towards learning, and alertness is termed a dispositional view of thinking. Researchers assert that VT can develop learners' abilities and motivate them to learn (Salmon, 2010a; Ritchhart et al., 2011).

Tishman and Palmer (2006) assert that VT has a twofold goal: on the one hand, to cultivate students' thinking skills through engagement and enhancing participation, and on the other hand, to deepen content learning and enhance students' understanding. VT helps create learners who are open minded, curious, critical, and, at the same time, skeptical. Salmon (2008) likewise asserts the importance of thinking routines by elaborating that "Thinking routines are powerful resources that assist teachers in understanding their students' inner processes of mind" (p. 126). She also discusses thinking routines as a means to make thinking visible by saying,

Visible thinking is achieved by observing how students internalize their thoughts in English language classrooms. It is an approach to teaching and learning that emphasizes the use of thinking routines and documentation to make thinking more visible in classrooms. Thinking routines are easy-tolearn structures, mostly taking the form of simple sets of questions or metaphors that naturally involve students in thinking processes. These routines may expand the students' repertoire of cognitive strategies, because the routines constitute a major form of organizing memory and thinking. (p. 366)

Collectively, VT is a teaching method that helps teachers observe their students' thinking processes and discover their prior knowledge, their reasoning abilities and the difficulties and challenges they face or encounter. VT helps teachers create situations that allow students to participate and share with others to develop and enhance their intellectual development. Involving students in the learning process and providing them with opportunities to work in pairs or in groups, helps them create a culture of thinking through which they can reflect upon the different responses and perspectives they receive from their peers (Ritchhart, 2015).

I suggest that making thinking visible through the application of thinking routines has potential to assist teachers, educators and parents to become more aware of the importance of developing thinking skills and to assist students to always articulate their thoughts and their understanding. This study can provide a practical and theoretical framework for the Palestinian educators to assist building a culture of thinking that could be primarily part of improving students' learning and part of reforming and transforming education in Palestine. This study could also be part of the ongoing professional development of English language teachers through the practice of reflection. It can provide an example of how to shift the classroom culture toward students who are engaged in thinking and learning and who are always exploring ideas, seeking deeper understanding and practicing skills that are needed in everyday life. 
This research provides evidence that a more learner-centered dynamic classroom model in which students are engaged in thinking activities is better than a content based memorization and test driven education model. It provides evidence that the use of thinking routines is a preferred pedagogy for second language acquisition.

Thinking-routine activities acted as inquiry, a means of experimentation and reflection through the oral discussion that occurred in an English language classroom. Ritchhart and Perkins (2008) in their study "Making Thinking Visible" emphasize that "When learners speak, write, or draw their ideas, they deepen their cognition" (p. 57). They also argue that "Fostering thinking requires making thinking visible" (p. 58). In this project, students' engagement and participation made students' thinking visible and available for questioning, reviewing, and modifying.

\section{Definitions of Key Concepts}

Thinking: Thinking is an active process intimately connected with language (Fernyhough, 2009).

Visible thinking: It is a broad and flexible framework for enriching classroom learning in the content areas and fostering students' intellectual development at the same time.

Thinking routines: Structures, through which students collectively as well as individually initiate, explore, discuss, document, and manage their thinking. These structures are explicit, instrumental, easy to learn and easy to remember. Thinking routines are applicable and useful across a variety of contexts (Ritchhart, Palmer, Church, \& Tishman, 2006).

Culture of thinking: Places where an individual thinking or a group collective thinking is valued, visible, and actively promoted as part of the regular, day-to-day experience. Language, time, opportunities, routines, modeling, interactions, and expectations are the forces of the culture where teachers strive to create in order to develop cultures of thinking in their classrooms (Ritchhart, 2002).

\section{The Limitations and the Assumptions of the Study}

There are several limitations to this qualitative study. This study is restricted in both the number of teachers and the grade of students. Only six teachers volunteered to participate in this research and only fourth- and fifth-grade students were involved. Similarly, it is limited to the time of its application as it lasted only one school semester. The limitation of the language for many students was also a challenge, and thus, this forced them to refer to their mother tongue "Arabic language."

\section{Research Design}

\section{Research Subjects}

Two private schools and six teachers from Jerusalem-Palestine volunteered to participate in this action research as a collaborative effort to grow and improve their professional practices. Four teachers teach in boys' elementary school and two in girls' elementary school. As mentioned earlier, the implementation of this research was on students in fourth and fifth grades. The researcher chose these two private schools as she was the supervisor and the consultant for both schools and the teachers who volunteered taught these stages. 
I chose to conduct this study on these elementary stages because many researchers assert that learning a second language at early stages is very critical and crucial for language development. These early stages develop important literacy and thinking skills and are the foundation for success of learning and acquiring a second language (Roskos \& Neuman, 2003; Shonkoff \& Phillips, 2000; Tabors \& Snow, 2001).

\section{Time of Research Implementation}

Data collection extended for more than one semester term. From the beginning of the second semester in the school year 2014 until the beginning of the first semester of the school year 2015, teachers experimented with a thinking-routines approach. They practiced documenting students' thinking throughout English language classrooms so as to analyze their documentation with their colleagues and with the researcher during the biweekly meeting.

\section{Methods of Data Collection}

In this study, the researcher adopted a qualitative study method as to ensure that the application of thinking routines is explored. The methods were classroom observations and field notes, videotaping, collecting and discussing teachers' and students' written and oral reflections on the implementation of thinking routines.

In this qualitative study, the researcher observed and videotaped English language classes for the fourth and fifth grades on a weekly basis, collected teachers' and students' reflection and met them twice a month for a period of 5 months to discuss and get some oral feedback (in addition to their journal written feedback) on the implementation of thinking routines in English language classes.

During the data collection process, the researcher categorized the data and began an ongoing data analysis. As commonalities arose among the data collected from different sources, the researcher addressed these commonalities by comparing them with the field notes taken during classroom observation and discussions with teachers and students all to provide the triangulation of the data.

\section{Procedures for Implementation}

Before embarking the project, English language teachers were to explore their own understanding of thinking routines and this was achieved by presenting and discussing the implementation with the researcher. During two training sessions, it was emphasized that VT is a pedagogical approach to teaching and learning that emphasizes the use of thinking routines and documentation to make thinking visible in English language classrooms.

Teachers were asked to read some articles about thinking routines, including the summary that was provided by the researcher for the core of thinking routines. Teachers were advised to watch You Tubes about the implementation of thinking routines in classrooms, talk with other teachers who have implemented thinking routines, and observe each other's implementation. Teachers were also asked to discuss and write their reflection on their own and on their peer practices as to help themselves and others improve thinking-routine implementation. Obviously, this was a good start to implement thinking routines and study its impact on increasing students' engagement and on improving their understanding that might lead to better English language teaching and learning. 


\section{Results}

The results showed that the implementation of VT routines in Palestinian English language classrooms was a challenge for both the learners and the teachers. For the learners, the challenges were their limited abilities to express themselves using English language and the dominance of better English language learners. While for the teachers, the challenges were the extra effort that they needed to exert because it was their first experience in implementing such routines. The limited place in the class and the large number of students were also a challenge because most of these activities required students to work in pairs and in groups. Teachers were to spend more time modeling and making students thinking visible and students were to realize that thinking routines should be part of their classroom thinking patterns.

From the various qualitative data collection methods, it was revealed that students' engagement was initially limited, but when thinking was part of everyday classroom routine, students' engagement improved. Through the ongoing practice, students were encouraged to explore, discuss, question, document, dialogue and direct their thinking and learning. Teachers reported that some positive changes occurred in English language classrooms and in students' learning. They expressed their admiration of how students started to explore and connect ideas and how they expanded and led ideas into new orientations or new directions that helped them dig deeper in contents they were studying. Classroom activities became more enjoyable, spirited and memorable.

For example, in the think stage for the "see, think, wonder" routine, to teach the poem "Free to Roam" by Leon Rosselson (2009/1994), the teacher gave each group of fifth-grade students a cage and asked them to cage the animals they hold. Then, she asked students, "If you were this animal, how would you feel? What would you do to be free?" Part of the conversation was like this:

Teacher: How would you feel if you were caged?

A Student representing his group: If I were caged, I would feel bad, miserable, very sad, angry, I would not feel my freedom.

Another student: If I were caged, I would feel very sad, unhappy. I would be angry ... [hesitating, not able to pronounce the word "resist"] ... Palestinians are not free, they are caged by the apartheid wall ...

The conversation and the discussion of the concept "Free to Roam" continued.

In the poem-writing activity, students were required to write a short poem to share with their classmates. During this activity, the teacher was able to discover one of the talented students who wrote,

From every Palestinian child's, heartbeat

with the green branch of the olive tree

growing in every garden, or street

with the sunrise, in the active hearts

with birds that merrily for ambition, beauty and freedom tweet. 
As a matter of fact, the implementation of thinking routines in order to teach this poem motivated students to be engaged and involved in most classroom activities. Students took more active roles and were able to express themselves using English language in most of the activities. Thinking routines were opportunities for students to practice English and to improve their communication skill.

Teachers reflected that some thinking routines were used more than others in English language classes. Nevertheless, these thinking routines activated students' knowledge and helped them learn some new words and concepts. Some students used their mother tongue in activities that demanded deep thinking as a result of using thinking routines, but this did not contradict teachers' purpose of enhancing students' engagement and fostering their understanding as stated earlier. Lambert (1981) stated that giving students opportunities to express themselves in their mother tongue help them gain confidence in their abilities, open their minds and enrich them intellectually.

Furthermore, students had learned the importance of monitoring and directing their own thinking processes because teachers tried hard to emphasize the role of metacognition as it plays a very essential role in students' everyday thinking and problem solving. Teachers in their ongoing reflection remarked that making thinking visible through the implementation of thinking routines, enabled them to observe and assess their students' thinking processes and their understanding. They were able to identify areas of strengths and weaknesses of their students and to work hard on consolidating and reinforcing students' strengths and in addressing weaknesses. English language teachers commented that the implementation of thinking routines was a good way to uncover students' thoughts, beliefs, opinions, attitudes and the most important of all some misconceptions.

Additionally, and as a result of thinking-routine activities, teachers were able to explore some talented students who were able to think in a scientific way. For example, in one of the activities in which fifth-grade students were discussing the concept of competition, students were to act as a judge and set criteria to decide the winner poster. These students identified three criteria: the color, the size, and the clarity of the poster. The color was given the number 1 , the size was given the number 2 , and the clarity was given the number 3 . The posters were lettered from A to $\mathrm{K}$. Then, the students drew a table to identify the winner poster. This table helped students organize their ideas to reach the winning poster (see Appendix C). Students' understanding was visible through their explanation and through answering the questions raised either by the teacher or by their peers. Working in groups in this activity helped students discuss the concept with each other and dialogue their decision to reach the best poster based on the criteria they set together.

English language teachers expressed that they were having some concerns regarding the implementation of thinking routines, especially at the beginning, but when implemented, they were really impressed by the different ideas that students were able to state. Different facets of understanding were revealed, students were able to explain, interpret and sometimes apply their understanding through the mini projects that they were required to do.

The results are compatible with what Ritchhart (2002) emphasized. He stated that "thinking routines can become part of the classroom culture through repeated practice. They can create patterns of thinking and learning that become part of the students' intellectual character" (p. 2). So, by applying more thinking routines in English language classrooms, teachers and students will be able to build "the culture of thinking" (p. 2) that is needed to enhance students' learning. 


\section{Discussion}

Making thinking visible in English language classrooms provided students with vivid models of what processes of good thinking looked like and showed them how their engagement and participation in their classrooms helped them get deeper knowledge and deeper understanding. Being engaged in classroom activities encouraged them to practice English language and to raise questions in spite of the mistakes committed and in spite of referring to the Arabic language in some activities.

For example, in the fourth-grade class, in the thinking stage in one of the English language lessons, the teacher asked such questions: "How much sugar is there in a can of cola?" and "How much fat will you find in a can of cola?" Such questions trigger students' minds to raise other questions in the wonder stage; questions that had reflected their understanding such as, "Because white chocolate is white, does it have more milk than brown chocolate?" "Why do we have factories for manmade sugar?" "Why do people like sugary food?" "How can we live without chocolate?" "Why do all people like chocolate?" "What is pure dark chocolate?" "Why is dark chocolate good for the brain?" "Why are sweets bad for our teeth?"

These were just some of the many questions that made students delve into deeper thinking in their lesson "Keep Your Teeth Healthy." The wonder stage was very important to help students raise some questions and check their answers. It is the inquiry skill that teachers sought to invest in their students through these processes.

In another example, one of the teachers explained in her reflection about thinking-routines implementation,

It seems that my students liked "think, puzzle, and explore" routine. It really makes the invisible thinking visible. If you see the poster, which was done by my students, you will notice think-puzzle-explore in their poster.

\section{Think:}

- Olive trees are popular in Palestine.

- Olive trees are useful.

- Olive trees are most in the north of Palestine.

- We make soap from olive trees.

- We make oil from olive trees.

- Olive trees give Palestine special aspect.

- Olive trees hold religious and cultural significance to the Palestinians.

\section{Puzzle:}

- What are the benefits of olive trees?

- How old are the olive trees in Palestine?

- How many olive trees are in Palestine?

- What are the roles of Palestinian farmers toward olive trees?

- When do farmers harvest the olive trees?

- Where is the common place for olive trees?

- Why do settlers burn Palestinian olive trees? 


\section{Explore:}

- Searching on the internet.

- Write posters about olive trees.

- Ask students' parents and grandparents.

- Make interview with farmers.

For more teachers' reflections, see Appendices A and B.

Undoubtedly, thinking routines in English language classrooms consisted of a series of questions that were generated by teachers and students. Students were not only responding to teachers' questions, but they were generating questions in order to develop their understanding and help them construct meaning that lead to the steps of critical thinking and problem solving. These routines supported the students' development as self-directed learners and promoted their understandings and their curiosity to learn and to raise questions. There are growing evidences from studies (Billmeyer, 2006; Harvey \& Goudvis, 2000) that emphasize the importance of questioning. Questioning usually challenged young learners' intellect and helped them understand. Moreover, encouraging students to raise questions fostered a community of inquiry that enhances classroom discussions and students' participation.

The results also showed that some thinking routines had been used more than others in English language classes. The routines "see, think, wonder," "think, pair, and share," "I used to think... And now I think/understand," and "think, puzzle, explore," were the most salient ones. One of the reasons might be because teachers sometimes found it difficult to decide which routine was the most appropriate for the designed activity. The other reason might be related to the level and the limited language that young students have. However, this experience showed that the implemented routines guided students to better understanding and helped them better practice how to think for themselves instead of just depending on rote memorization or on spoon-feeding by the teacher.

During the implementation of thinking routines, teachers had the opportunity to test their own understanding of VT through their reflection. Teachers felt that they needed to reshape their implementation and to adopt more strategies to promote more thinking routines in their classrooms as to nurture their students' thinking skills. However, teachers complained that they need more classes to be able to achieve and gain better results in cultivating a culture of thinking.

Teachers believed that this experience helped them think about their own practices as teachers. They realized that they could improve English language teaching by taking serious steps that encourage students to learn English through practicing the skills required for better thinking processes and better language learning especially when it is recognized that language is the core of thinking. For example, English language teachers realized that for elementary students to think and explore ideas deeply, they need concrete objects or any source of visual aid to focus students' thinking. For that reason, teachers in later stages started to use concrete objects and visual aids as to help students be more involved in the thinking process that the activities required.

It was obvious that through thinking routines, students and teachers could generate ideas, analyze, reason with evidence, make connections, summarize, pose questions, interpret, visualize, clarify, observe closely, identify and explore multiple perspectives, build explanations, synthesize information, look below the surface of things, predict, evaluate and look at patterns. Actually, all these are the levels of thinking that teachers were to emphasize to make thinking visible and make English lessons more fruitful. 
Students' reflection reported that they enjoyed their English classes more than before and they were more motivated and secured to use English language in their classes. They also emphasized the importance of working in pairs or in groups as this helped them learn better.

Students and teachers realized that it is time to move from the story of only finishing the work, covering the textbooks, testing students' superficial knowledge to the story of enhancing and improving learning; learning that can be carried to the rest of life as it becomes a thoughtful routine process.

Costa (2008) pointed out that skillful thinking must be refined through solving problems and helping students become creative thinkers. These patterns of conversation ("see, think, wonder," "think, puzzle, explore," "think, pair, share," "circle of viewpoints," "I used to think ... and now I think," "color, symbol, and image," and many others) make students' thinking visible. Students will be able to explore and analyze English language topics and develop deeper and broader understandings.

\section{Analysis}

The analysis of the results showed that thinking routines are vital approach because they represent patterns of behavior that teachers adopt to help students use their intellectual abilities in different situations. Teachers need to advance their students' understanding by providing them with thinking-routine activities that make their thinking visible to their teachers, to their peers, and at the same time to encourage them to actively engage in learning and thinking beyond the facts and beyond rote memorization or shallow learning. Thinking routines should be integrated and used in a variety of contexts to help students develop different levels of thinking, including their metacognitive thinking skills (Salmon, 2010b, 2011).

Although the implementation of thinking routines in Palestinian English language classrooms was a challenge for both teachers and learners, especially at the beginning, the actual implementation assured the positive changes that took place in their journey of learning. Teachers revealed that the implementation of thinking routine helped them to model and teach thinking skills in an explicit way. Students realized that learning is not a matter of just repeating information or having a good grade in a test, but it is more based on developing thinking skills as students explore English language texts. Through thinking routines students were able to demonstrate and question their understanding; they were able to critically think about what was presented in their English language classes. The implementation of thinking routines motivated students to participate and express themselves, even if they were not able to produce correct English sentences or express their thoughts in English language. Moreover, students benefited from the collaborative thinking while working in groups.

Again, moving from the journey of work to the journey of learning, teachers began to explore their definition and understanding of thinking routines through reading, discussing and watching YouTube. They reflected on their implementation of thinking routines and modified their practices by adapting and adopting new strategies to cope with all the challenges they faced. The analysis of the results revealed the importance of fostering a community of inquiry among teachers and students. One of the teachers commented,

I think as a teacher, it is time to start asking myself questions related to insisting on my students completing and doing homework. I should start asking if my students learn what they are supposed to learn with better understanding. I should also ask if my students retain the learning over time, 
if they can use English language to express themselves, and if they can use this learning in ways that demonstrate their deep understanding. I should ask if learning enhances my students' skills, skills that they need to be equipped with for a better life. This research is really an opportunity for us as teachers to reflect and assess our own teaching strategies.

\section{Recommendations}

In the light of the research results, the following recommendations were stated. First, the fact that these thinking routines have only a few steps make them easy to teach and learn; therefore, Palestinian teachers teaching other subjects are recommended to use these routines to help students develop the skill of ongoing-inquiry. Second, it is necessary for the Palestinian teachers to bring appropriate content to the routine. The routines are not the content; they are vehicles for exploring the content. Third, teachers are recommended to create their own thinking routines, implement and share with other teachers. Fourth, it is also essential to devote enough time for exploration, planning, and discussion of VT that helps to maintain focus of teachers' professional practice. Teachers can share classroom practices with their colleagues regarding learning new routines and planning for the application of new thinking routine for future instruction. Fifth, it is recommended to introduce thinking routines quite earlier in schools, starting from earlier stages. Sixth, teachers need to think about their questioning techniques. They should always ask questions that shape their students thinking ("Where else have you seen something like this?" "Why is this the way it is?" "How does this connect to the topic you have been studying?" "If you were to group these things, what would go together?" etc.). Seventh, teachers should realize that using thinking routines is a process that takes time and needs practice; therefore, they need to be patient, persistent, perseverant, consistent and risk taker. Eighth, as part of the ongoing professional development, teachers are recommended to devote one meeting or two every semester for exploration, planning, and discussion of VT as this might help in maintaining a focus and help in growing the ideas and practices of teachers. Teachers can share their successful classroom practices and they can discuss challenges and means to overcome. Finally, it is recommended to include parents in the process of applying thinking routines by providing workshops to help and lead them.

\section{Conclusion}

Thinking skills are undeniably essential for dealing with the demand of the future which will be more complex and more competitive. The current study points the importance of making students' thinking visible through the implementation of thinking-routine activities as these activities facilitate students' on-going inquiry and enhance broader-deeper understanding. When teachers and parents understand the importance and the value of thinking, students will also realize that they should always delve beneath the surface by questioning, reading, seeking information ... to be better life long independent learners. With these thinking tools, students are given the opportunity to connect what they learn with their environment and with the life they live.

It would be very interesting if teachers and parents focus on developing thinking skills by incorporating various situations and settings as thinking skills should be valued at all academic levels starting from very early stages. So, if teachers and parents want their children to be good thinkers, they must guide and lead them. 
To conclude, this study explores some of the ways on how thinking skills could be enhanced and what English language teachers can do to improve their students' learning. But, at the same time, there is still a need for a continued investigation to study the impact of enhancing students' thinking skills through making students' thinking visible.

If teachers want to make their students thinking visible in English language classrooms, they need to use the processes of thinking routines as they provide a structure for making meaning and giving students an introduction to the process of thinking deeply and critically (Ritchhart et al., 2011). When these thinking routines are used regularly as part of classroom learning environment, they help in developing what Ritchhart (2002) called a "culture of thinking" (p. 2).

Through thinking routines, English language teachers will be able to generate and enliven rich classroom environment where more students' discussion and participation occur. Students will be able to compare, reason, analyze, justify, interpret, rationalize, deduce, create, evaluate, apply and reflect. All these are important skills in any learning environment, including learning a foreign language. Thinking routines could be seen as one of the methods or pedagogies that can enhance students' engagement in English language classrooms and thus cultivate a culture of critical and creative thinking.

\section{References}

America-Mideast Educational and Training Services. (2014). Leadership and Teacher Development (LTD) program. Retrieved from http://amideast.org/ltd/about-ltd/leadership-and-teacherdevelopment-ltd-program

Billmeyer, R. (2006). Strategies to engage the mind of the learner: Creating strategic learners (2nd ed.). Omaha, NE: Rachel \& Associates.

Costa, A. (2008). The thought-filled curriculum. Educational Leadership, 65, 20-24.

Dajani, M. (2015). Preparing Palestinian reflective English language teachers through classroom based action research. Australian Journal of Teacher Education, 40. Retrieved from http://dx.doi.org/10.14221/ajte.2014v40n3.8

Fernyhough, C. (2009). Dialogic thinking. In A. Winsler, C. Fernyhough, \& I. Montero (Eds.), Private speech, executive functioning, and the development of verbal self-regulation (pp.42-52). Cambridge, United Kingdom: Cambridge University Press.

Harvey, S., \& Goudvis, A. (2000). Strategies that work: Teaching comprehension to enhance understanding. Portland, ME: Stenhouse Publishers.

Khaldi, M., \& Wahbeh, N. (2002) The role of the supervisory system: Realties and needs, unpublished paper. Ramallah, Palestine: QCERD.

Kouhail, H. (2004) Vocational technical education and training in Palestine: Proposal for a national strategy. Ramallah, Palestine: Ministry of Education.

Lambert, W. E. (1981). Faces and facets of bilingualism. Bilingual education series, 10. Washington, DC: Center for Applied Linguistics.

Ritchhart, R. (2002). Intellectual character: What it is, why it matters, and how to get it. San Francisco, CA: Jossey-Bass. 
Ritchhart, R. (2015). Creating cultures of thinking: The 8 forces we must master to truly transform our schools. San Francisco, CA: Jossy-Bass.

Ritchhart, R., Church, M., \& Morrison, K. (2011). Making thinking visible: How to foster engagement, uncover understanding, and independence for all learners. San Francisco, CA: Jossey-Bass.

Ritchhart, R., Palmer, P., Church, M., \& Tishman, S. (2006, April). Thinking routines: Establishing patterns of thinking in the classroom. Paper presented at AERA Conference, San Francisco, CA.

Ritchhart, R., \& Perkins, D. (2005). Learning to think: The challenges of teaching thinking. In K. J. Holyoak \& R. G. Morrison (Eds.), Cambridge handbook of thinking and reasoning (pp. 775802). New York, NY: Cambridge University Press.

Ritchhart, R., \& Perkins, D. N. (2008). Making thinking visible. Educational Leadership, 65, 57-61.

Roskos, K., \& Neuman, S. B. (2003). Environment and its influences for early literacy teaching and learning. In S. B. Neuman \& D. K. Dickinson (Eds.), Handbook of early literacy research (pp. 281-294). New York, NY: Guilford Press.

Rosselson, L. (2009). Questions: Songs and stories for children. Oakland, CA: PM Press. (Original release 1994)

Salmon, A. K. (2008). Promoting a culture of thinking in the young child. Early Childhood Education Journal. 35, 457-461.

Salmon, A. (2010a). Engaging young children in thinking routines. Childhood Education, 86, $132-137$.

Salmon, A. (2010b). Making thinking visible through action research. Early Childhood Education Journal. 39, 15-21.

Salmon, A. (2011). Thinking routines. Teaching Young Children, 5, 18-22.

Shonkoff, J., \& Philips, D. (Eds.). (2000). From neurons to neighborhoods: The science of early childhood development. Washington, DC: National Academy Press.

Tabors, O., \& Snow, C. (2001). Young bilingual children and early literacy development. In S. B. Neuman \& D. K. Dickinson (Eds.), Handbook of early literacy research. New York, NY: Guilford Press.

Tishman, S., \& Palmer, P. (2006). Artful thinking: Strong thinking and learning through the power of art. Cambridge, MA: Harvard Graduate School of Education. 


\section{Appendix A}

\section{Fourth-Grade Teacher Reflection}

My reflection is on today's lesson which was about sugar and its effects on human health in a negative way. By using VT skills, I have noticed that my students are more motivated in their learning. They are less bored during the lesson because they are required to do more thinking than just receiving information. For example, questions sprang up such as, "Because white chocolate is white, does it have more milk than brown chocolate?" "Is eating too much manmade sugar poisonous to your body?" "If sugar is bad for you, then why do companies make and sell sugar to people?" These are just some of the many questions that made students "wonder" or start using the thinking process.

VT also gives students an opportunity to practice expressing themselves orally through conversation, writing and reading what they have written. When students read what they have written, this makes them notice their grammatical and spelling errors. Students learn more effectively when they notice their own mistakes and correct them. The challenges for students are their limited abilities to express themselves using English language. There is a language barrier in most of the classes. In other words, students do not speak English fluently that help them express their thoughts easily. We need to implement better techniques to improve fluency in the English language in order to obtain better results for the VT approach. VT is a slow process in the beginning because it requires a lot of hard work to achieve positive results. Yet, patience, persistence, and consistence are the keys for teachers to make students become successful English language learners. 


\section{Appendix B}

\section{Fifth-Grade Teacher Reflection}

In order to improve the traditional ways of teaching and learning, we always try to apply new techniques and routines in our classes. Recently, in my class, I applied some of the routines in order to make my students thinking visible. This routine is called "see, think, and wonder."

The main goal of this lesson was to teach the concept of competition and what is related to it, such as winning, losing, competitor, judges, and criteria. In order to save time, I prepared the classroom in advance. Posters were hung and chairs were arranged for students to work in groups.

As a warm-up activity, I held a short competition between three students. A prize was given as a reward for the one who blew the biggest balloon within $10 \mathrm{~s}$. In this activity, I asked my students several questions to go through the process "see, think, and wonder." For example, I asked, "What can you see?" "What colors are they?" "What do you think are we going to do?" "What do you think the winner should get?" We went through the activity and I gave the winner a prize. It was extremely a good way to motivate students and to encourage them to participate.

Then I told my students that we are going to move to a longer competition. In the see stage, I asked my students many questions to grab their attention to what we are going to do next. The questions were, "What can you see?" "Can you notice the name labels on the posters?" "How many posters do we have?" "Are they the same color and size?" The students answered these questions easily. After that, I told the students that we are going to hold a competition to choose the best poster and that they are going to be the judges.

In the think stage, I asked my students, "Does judging need deep thinking?" "If your friend's poster is in this competition, would you choose it just to strengthen your friendship?" "As a judge in such competition, will you have criteria to take into consideration before making your decision?"

Most students agreed on having criteria before judging on the best poster. I asked them to explain their answer. One of the students said, "It won't be fair if I don't have a certain criteria before judging." Therefore, I asked the students to act the role of judges and to work in groups. Each group should think of criteria to use in order to choose the best poster. Students shared their ideas and they wrote their notes on a flip chart.

Afterwards, a student from each group presented what they had written. I let the other groups comment on or ask the presenter about his group's points which enabled and encouraged students to ask for explanation or to raise their questions freely. After that, I asked the groups of judges to use the criteria that they had set in voting for the best poster.

At the end, we announced the winner poster and I asked them to vote for a suitable reward for the winner. In the last few minutes, I asked my student to prepare at home questions and wonders about this class.

The next day, they asked many questions, and wonders were raised. Some of their questions were, "Did we do that to act the role of judges?" "Did we do that to work as a team?" "Did we do that to have fun?" "What was the goal of this class?" "Why didn't we work in our class?" "Why didn't we work in groups all the time?" "Why don't we have technical materials for voting?" "Why didn't we work 
with the other fifth graders in the school?" "Why didn't we work individually?" "Why didn't we share the gift?" "Why did you videotape the class?"

Although some of the instructions were not clear to many students because of language limitation, I tried to use many ways to get them involved in the group work. For example, I meant to give examples or to ask other students to illustrate what we are going to do. However, all the students enjoyed the class. Students asked that all classes should be in this way. 


\section{Appendix C}

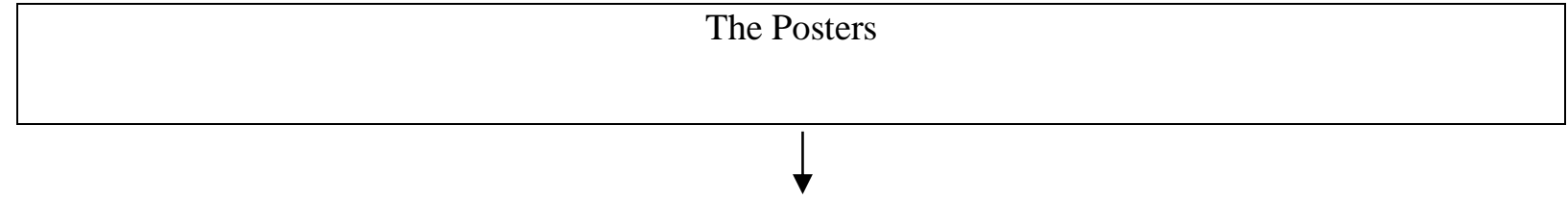

\begin{tabular}{|c|c|c|c|c|c|c|c|c|c|c|}
\hline A & B & C & D & E & F & G & H & I & J & K \\
\hline 2 & 1 & 1 & 1 & 1 & 1 & 1 & 1 & 1 & 1 & 1 \\
\hline 3 & 2 & & & & & 2 & 2 & 2 & 2 & 2 \\
\hline & 3 & & 3 & 3 & 3 & & & & & 3 \\
\hline
\end{tabular}

